\title{
Pulmonary Function Changes Before and After Mitral Valve Surgery in Severe Mitral Stenosis
}

\author{
Manoj Kumar Sahu ${ }^{1}$ Mayank Yadav ${ }^{1}$ Milind Padmakar Hote ${ }^{1}$ Sarvesh Pal Singh ${ }^{1}$ Shiv Kumar Choudhary ${ }^{1}$ \\ ${ }^{1}$ Department of Cardiothoracic and Vascular Surgery, All India \\ Institute of Medical Sciences, New Delhi, India

\begin{abstract}
Address for correspondence Manoj Kumar Sahu, MD, DNB, Department Centre, All India Institute of Medical Sciences, New Delhi 110029, India (e-mail: drmanojsahu@gmail.com).
\end{abstract} \\ of Cardiothoracic and Vascular Surgery, CTVS Office, 7th Floor, CN
}

\begin{abstract}
Keywords

- mitral stenosis

- mitral valve replacement

- pulmonary function tests

- NYHA class

Objective This study was undertaken to assess the pulmonary functions in the patients with predominant severe mitral stenosis before corrective mitral valve surgery, then to reassess the same 6 months after surgery and compare them.

Patients and Methods Fifty consecutive patients with predominant severe mitral stenosis undergoing mitral valve replacement surgery were included in this prospective observational study. This study was conducted from July 2016 till January 2018 after obtaining approval from the institute's ethics committee and written consent from all the participants. All the patients were evaluated clinically and divided according to New York Heart Association (NYHA) class symptomatology. Computed spirometric pulmonary function tests (PFTs) such as forced vital capacity (FVC), forced expiratory volume in 1 second $\left(\mathrm{FEV}_{1}\right), \mathrm{FEV}_{1} / \mathrm{FVC}$ ratio, forced expiratory flow (FEF) 25-75\%, peak expiratory flow rate (PEFR), and maximum voluntary ventilation (MVV) were performed on each patient 1 day before and 6 months after surgery.

Results Fifty study patients were analyzed, mean age was $38.4 \pm 10.76$ years (15-56 years), and male-to-female ratio was 1:1.38 (21 males and 29 females). NYHA class symptoms improved significantly in most of our patients after surgery $(p<0.01)$. PFTs such as FVC, FEV1, FEV $/$ /FVC ratio, FEF 25-75\%, and MVV showed significant improvement 6 months after surgery $(p<0.01)$. Though PEFR also improved compared with preoperative values, it was not significant statistically $(p<0.07)$.

Conclusion This study showed that the lung functions are impaired in patients with severe mitral stenosis and improved significantly 6 months after surgery, which does not correlate well with the betterment of NYHA class.
\end{abstract}

\section{Introduction}

Exertional dyspnea and poor exercise tolerance are the common symptoms in patients with mitral stenosis (MS), associated with deranged lung functions. MS manifests as typical restrictive abnormalities of pulmonary functions due to reduced compliance, increased airway resistance, and reduced diffusing capacity resulting from pulmonary congestion and pulmonary vascular disease. In severe MS, a high-pressure gradient (up to $20 \mathrm{~mm} \mathrm{Hg}$ ) across the mitral valve is required to maintain normal cardiac output at rest. ${ }^{1}$ Thus the increase in left atrial pressure
(LAP) raises the pulmonary venous pressure (PVP), which ultimately increases pulmonary arterial pressure (PAP) as the disease progresses. In up to $20 \%$ patients, the pulmonary vascular resistance is also elevated, which increases PAP. ${ }^{2}$ The chronic changes in pulmonary circulation cause alterations in pulmonary vasculature and pulmonary parenchyma. Water and proteinaceous fluid leak into the interstitium as the PVP increases leading to repeated lung congestion and pulmonary edema as the severity of MS increases. These interstitial changes are the basis of the clinical manifestations of MS and can be detected by pulmonary function tests (PFTs). ${ }^{3}$
DOI https://doi.org/ 10.1055/s-0039-1684879 ISSN 2457-0206.
Copyright @2018 Official Publication of The Simulation Society (TSS), accredited by International Society of Cardiovascular Ultrasound (ISCU).
License terms

(2) (1) $\ominus \circledast$ 
Therefore, it is clear that MS is complicated by pulmonary hypertension of varying degrees. The hemodynamic derangement is associated with structural changes in the pulmonary vessels and parenchyma, which leads to functional derangements. Pulmonary mechanics are further disturbed after cardiothoracic surgery that manifests like restrictive pathology, which may persist for weeks to months postoperatively. ${ }^{4}$

This study was performed to assess the changes as well as the reversibility of PFTs after corrective surgery for MS.

\section{Patients and Methods}

This prospective observational study conducted in the department of cardiothoracic surgery at a tertiary care teaching hospital in north India. The work was performed from July 2016 till January 2018, after obtaining permission from institute's ethics committee and written, informed consent from all patients.

Fifty consecutive patients between 15 and 60 years of age with predominant severe MS were included in this study. There were 21 males and 29 female patients ( $M: F=1: 1.38$ ). Eight $(16 \%)$ patients had mild mitral regurgitation, 26 (52\%) had mild tricuspid regurgitation, and $2(4 \%)$ had mild aortic regurgitation. Most patients $(n=24,48 \%)$ were in the age group of 36 to 45 years (male/female $=9 / 15$ ). All these patients underwent mitral valve replacement for MS electively. Mechanical prosthetic valves were implanted in all the patients. Seven patients underwent percutaneous balloon mitral valvotomy, and none of these patients ever had any cardiothoracic surgery before. Patient demographics and intraoperative variables were described in - Table 1 .

Preoperatively all patients underwent clinical evaluation and were subdivided on the basis of New York Heart Association (NYHA) class symptomatology, and the distribution was like this: 3 (6\%), 13 (26\%), and 34 (68\%) patients were in NYHA classes I, II, and III, respectively.

Pulmonary function tests were done by computed spirometry (RMS spirometer, Helios 401, Care Medisystems) 1 day before and 6 months after surgery for each patient. Forced vital capacity (FVC), forced expiratory volume in 1 second $\left(\mathrm{FEV}_{1}\right), \mathrm{FEV}_{1} / \mathrm{FVC}$ ratio, forced expiratory flow (FEF) 25-75\%, peak expiratory flow rate (PEFR), and maximum voluntary ventilation (MVV) were documented. PFTs were performed according to the recommendations of the American Thoracic Society. Our protocol is to teach patients how to perform spirometry before and after surgery for better recovery of lung functions post-surgery. We advise them to continue

Table 1 Demographic and intraoperative data

\begin{tabular}{|l|l|}
\hline Total patients & 50 \\
\hline Age (mean \pm SD) $(\mathrm{y})$ & $38.4 \pm 10.76$ \\
\hline Male-to-female ratio & $1: 1.38$ \\
\hline Weight $(\mathrm{kg})$ (mean \pm SD) & $60.2 \pm 7.3$ \\
\hline AOCX (min) (mean \pm SD) & $40.32 \pm 3.6$ \\
\hline CPB (min) (mean \pm SD) & $61.38 \pm 7.7$ \\
\hline
\end{tabular}

Abbreviations: CPB, cardiopulmonary bypass; SD, standard deviation. spirometry till 1 month after surgery, until the sternum is healed.

Patients with primary pulmonary disease; musculoskeletal involvement of the chest and thoracic spine, with concomitant other significant heart disease (valvular/ nonvalvular), chronic kidney, and liver disease; who are unable to perform spirometric exercises or with NYHA class IV symptoms; those who were smokers, undergoing emergency operations, and did not wish to participate in the study were excluded from the study.

All patients underwent mitral valve replacement via median sternotomy on standard cardiopulmonary bypass under mild hypothermia $\left(32^{\circ} \mathrm{C}\right)$ by one surgical team. All patients were managed in the cardiac surgical intensive care unit with uniform standardized protocol for antibiotics, analgesics, anticoagulation, weaning off ventilator support, early mobilization, and chest physiotherapy. Three patients were reoperated for mediastinal bleeding on the same day of surgery.

\section{Statistical Analysis}

The data were analyzed using the SPSS software version 20 (SPSS, Inc.). Continuous variables were expressed as mean and standard deviation. The categorical variables were expressed as number and percentage. Quantitative data were analyzed by application of student $t$-test/Mann-Whitney test. Qualitative data were analyzed by chi-square test or Fischer's test, whichever applicable. A $p$ value $<0.05$ was considered as significant.

\section{Results}

Total 50 patients were analyzed. The mean age of the study population was $38.4 \pm 10.76$ years ( $15-56$ years).

Breathlessness was the presenting symptom in most patients ( $n=42,84 \%$ ). Other symptoms documented were palpitation $(n=28,56 \%)$, cough $(n=14,28 \%)$, nocturnal dyspnea $(n=3,6 \%)$, and chest pain $(n=6,12 \%)$. A past history of rheumatic fever during childhood was present in 14 (28\%) patients, and history of cerebrovascular accident was present in $2(4 \%)$ patients. All these symptoms improved significantly after surgery as shown in - Table 2 .

- Table 3 shows the NYHA class distribution of the patients preoperatively and 6 months after surgery. NYHA class grading improved significantly in many of our patients after surgery. However, $52 \%$ of patients were still in class II

Table 2 Patient distribution according to preoperative symptomatology $(n=50)$

\begin{tabular}{|l|l|}
\hline Symptoms & $\begin{array}{l}\text { Preoperatively-No. of } \\
\text { patients (percentage) }\end{array}$ \\
\hline Breathlessness & $42(84 \%)$ \\
\hline Palpitation & $28(56 \%)$ \\
\hline Cough & $14(28 \%)$ \\
\hline Nocturnal dyspnea & $3(6 \%)$ \\
\hline Chest pain & $6(12 \%)$ \\
\hline Cerebrovascular accident (CVA) & $2(4 \%)$ \\
\hline
\end{tabular}


Table 3 Patient distribution according to NYHA class pre- and postoperatively

\begin{tabular}{|l|l|l|l|}
\hline NYHA class & Preoperative & Postoperative & $p$ Value \\
\hline I & $3(6 \%)$ & $19(38 \%)$ & $<0.01$ \\
\hline II & $13(26 \%)$ & $26(52 \%)$ & $<0.01$ \\
\hline III & $34(68 \%)$ & $5(10 \%)$ & $<0.01$ \\
\hline
\end{tabular}

Abbreviation: NYHA, New York Heart Association.

symptoms after 6 months, which was not well correlated with the lung functions at the same time.

The percentage predicted values of $\mathrm{FEV}_{1}, \mathrm{FVC}, \mathrm{FEV}_{1} / \mathrm{FVC}$ ratio, FEF 25-75\%, and MVV improved significantly 6 months post-surgery as compared with the preoperative values (-Table 4). PEFR also got better although the change was not statistically significant.

The average duration of mechanical ventilation was approximately 8 hours in the study population. Seven of our patients required short duration (up to 24 hours) of noninvasive ventilation post-extubation for retention of carbon dioxide and lung congestion. Minimal to moderate bilateral pleural effusions were noticed in 13 of our patients on first postoperative day in chest X-ray, all were managed conservatively, and none required chest tube insertion. No incidence of pneumothorax or acute respiratory distress syndrome occurred. Fourteen patients were in chronic atrial fibrillation (AF) before surgery, and they remained in AF postoperatively and were discharged home with a controlled ventricular rate with medications. All patients had good biventricular function, normal to mild PAP at the time of discharge from hospital. Almost all our patients had moderately enlarged left atrium (LA) $(30-45 \mathrm{~mm}$ size) preoperatively and did not decrease significantly at 6 months post-surgery. None of the patients had any neurologic deficit postoperatively.

\section{Discussion}

The effects of mitral valve disease on pulmonary functions are well known and include a reduction in spirometric volumes and carbon monoxide transfer with an increase in residual volume. ${ }^{5}$ The lung changes involve reduction in static and dynamic lung compliance, ventilation-perfusion mismatch, peripheral airway obstruction due to alveolar edema, and reduction in diffusing capacity (palmar et al). ${ }^{6}$

Lung changes in MS can either be reversible or fixed. Lung functions derange gradually as the disease advances in severity and manifests in the form of restrictive pattern; that is, FVC and FEV ${ }_{1}$ decrease progressively. This happens because of pulmonary venous congestion by backward pressure transmitted from raised LAP and ultimately lung congestion and pulmonary edema. The raised PVP leads to submucosal edema and airway compression by dilated vessels. Finally bronchial epithelial hyperplasia and bronchoconstriction occur causing some amount of airway obstruction and reduction in FEF 25 to $75 \%$ and PEFR. ${ }^{7}$

Mean age of our study population was $38.4 \pm 10.76$ years, and male-to-female ratio was 1:1.38. Both were comparable with the studies done by Chatterji, ${ }^{8}$ Saxena et al, ${ }^{9}$ and Mundhra et al. ${ }^{10}$

There was a significant clinical improvement in most of our patients. This clinical improvement was assessed by NYHA grading. Only 5 patients remained in NYHA class III, as compared with 34 . Nineteen patients improved to class I, and 26 patients were compared with 13 remaining in class II 6 months after surgery. All these changes showed a statistically significant improvement in NYHA class symptoms of the patients after surgery, as shown in - Table 3. Similar findings were observed in the study done in 1997 by Kadam et al. ${ }^{7}$ Though majority of our study population showed improvement from class III symptoms, many of them $(n=26,52 \%)$ were still in class II symptoms 6 months post-surgery, which was a surprising finding. And this was not well correlated with the improvements in all spirometric tests, except PEFR at the same time.

Our study showed that mean value of percentage of predicted FVC, $\mathrm{FEV}_{1}, \mathrm{FEV}_{1} / \mathrm{FVC}$, FEF 25-75\%, and MVV improved after the surgery. This change was found to be statistically significant and comparable to studies done by Kadam et al, ${ }^{7}$ Yoshioka et al, ${ }_{11}^{11}$ Mundhra et al, ${ }^{10}$ and Dogliotti et al ${ }^{12}$ ( - Table 5).

Predicted mean values of PEFR were found to be $69.2 \%$ and $71.5 \%$ pre- and postoperatively, respectively, a small improvement, but not significant statistically, which is comparable to other studies. ${ }^{9}$

This preoperative decrease in lung function in MS is due to high LAP and pulmonary hypertension, and that results

Table 4 Comparison of PFTs preoperatively and 6 months after mitral valve replacement

\begin{tabular}{|c|c|c|c|c|c|c|}
\hline PFTs & $\begin{array}{l}\text { Preoperative } \\
\text { mean value } \\
\text { (\% of predicted) }\end{array}$ & $\begin{array}{l}\text { Postoperative } \\
\text { mean value } \\
\text { (\% of predicted) }\end{array}$ & $\begin{array}{l}\text { Postoperative- } \\
\text { preoperative difference } \\
\text { in mean value }\end{array}$ & $\begin{array}{l}\text { Change } \\
(\%)\end{array}$ & $\begin{array}{l}\text { 95\% Cl (lower } \\
\text { limit-upper } \\
\text { limit) }\end{array}$ & $p$ Value \\
\hline FEV $_{1}$ & 66.58 & 86.02 & 19.5 & 23 & $15.8-23.2$ & $<0.01$ \\
\hline FVC & 73.64 & 82.86 & 9.22 & 11.1 & $6.61-11.8$ & $<0.01$ \\
\hline $\mathrm{FEV}_{1} / \mathrm{FVC}$ ratio & 90.41 & 105.5 & 15.09 & 14.3 & $11.94-18.23$ & $<0.01$ \\
\hline FEF $25-75 \%$ & 65.2 & 75.4 & 10.2 & 15.6 & $8.4-11.9$ & $<0.01$ \\
\hline PEFR & 69.2 & 71.5 & 2.3 & 3.3 & $-0.26-4.8$ & 0.07 \\
\hline MVV & 62.4 & 74.8 & 12.4 & 19.9 & $10.5-14.2$ & $<0.01$ \\
\hline
\end{tabular}

Abbreviations: $\mathrm{Cl}$, confidence interval; FEF, forced expiratory flow; $\mathrm{FEV}_{1}$, forced expiratory volume in 1 second; FVC, forced vital capacity; $\mathrm{MVV}$, maximum voluntary ventilation; PEFR, peak expiratory flow rate; PFT, pulmonary function test. 
Table 5 Comparison of pre- and postoperative PFTs in MS in different studies

\begin{tabular}{|c|c|c|c|c|c|c|}
\hline \multicolumn{2}{|c|}{ PFTs (pre- and postoperative values) } & Present study & Kadam et al & Mundhra et al & Dogliotti et al & Yoshioka et al \\
\hline \multirow[t]{2}{*}{$\mathrm{FEV}_{1}$} & PRE & $66.58 \%$ & $48 \%$ & $63.6 \%$ & $60.6 \%$ & $71.34 \%$ \\
\hline & POST & $86.02 \%$ & $61.16 \%$ & $72.9 \%$ & $71.68 \%$ & $78.32 \%$ \\
\hline \multirow[t]{2}{*}{ FVC } & PRE & $73.64 \%$ & $52.8 \%$ & $74.38 \%$ & $75 \%$ & $87.6 \%$ \\
\hline & POST & $82.86 \%$ & $60.8 \%$ & $81.23 \%$ & $82.4 \%$ & $94.7 \%$ \\
\hline \multirow[t]{2}{*}{$\mathrm{FEV}_{1} / \mathrm{FVC}$} & PRE & $90.41 \%$ & $81.72 \%$ & $86.06 \%$ & $80.8 \%$ & $82.1 \%$ \\
\hline & POST & $105.5 \%$ & $88.2 \%$ & $89.94 \%$ & $87.2 \%$ & $82.7 \%$ \\
\hline \multirow[t]{2}{*}{ FEF $25-75 \%$} & PRE & $65.2 \%$ & $58.28 \%$ & $64.56 \%$ & - & $69.3 \%$ \\
\hline & POST & $75.4 \%$ & $77.28 \%$ & $81.77 \%$ & - & $77.2 \%$ \\
\hline \multirow[t]{2}{*}{ MVV } & PRE & $62.4 \%$ & - & $67.27 \%$ & $59 \%$ & $66.6 \%$ \\
\hline & POST & $74.8 \%$ & - & $81.07 \%$ & $79 \%$ & $77.1 \%$ \\
\hline
\end{tabular}

Abbreviations: FEF, forced expiratory flow; $\mathrm{FEV}_{1}$, forced expiratory volume in 1 second; FVC, forced vital capacity; MS, mitral stenosis; MVV, maximum voluntary ventilation; PFT, pulmonary function test.

in the development of dyspnea. ${ }^{13}$ It has led many studies to provide a correlation between $L A P$, level of pulmonary venous hypertension, alveolar mucosal edema and congestion, narrowing of the smaller airways, and pulmonary arterial hypertension in a stepwise manner as the disease severity increases leading to permanent structural changes in the pulmonary vascular endothelium, ultimately affecting the changes in pulmonary functions, which manifests in the form of clinical class of dyspnea. Patients with similar lesions and PFT profiles may still present in different classes of dyspnea. Different studies have correlated pulmonary functions with the functional class. ${ }^{8} 14$ However, we in our study found that many patients $(52 \%)$ were still in class II 6 months post-surgery, which did not correlate well with the improvements in PFTs at the same time. However, the PEFR did not improve at the same pace, which probably was an indication that the small airways involved in the disease process may take more time to improve. Also, there could be the effect of duration of pathology (many of our patients were aged 36-45 years), which leads to some amount of obstructive airway changes for which many of our patients did not improve fast and were still in class II at 6 months.

Kadam et al found an initial decrease in PFTs but an improvement in the late postoperative period except in severe cases, and this early decrease was attributed due to thoracotomy pain. ${ }^{7}$ Saxena et al in their study stated that the pulmonary functions deteriorate immediately after surgery and then recover gradually over a period of 3 months; however, they remain below the predicted values. ${ }^{9}$ Like our findings, they also said that there was a poor correlation between the degree of change in PFTs and functional class, but we studied our patients 6 months post-surgery unlike them at 3 months. Chandra et al found that although there was an overall improvement in the spirometric parameters at 3 months after mitral valve replacement, the values remained lower than predicted. ${ }^{14}$ This study results showed that by 6 months postoperative period the lung functions improved significantly, but again they also remained below the predicted values.
Most patients in our study were in NYHA classes II and III and were extubated on the same day after surgery. All our patients had median sternotomy, and adequate pain control was achieved in the postoperative period. Aggressive chest physiotherapy and ambulation were started at the earliest. Their convalescence was mostly smooth, and clinical symptomatology improved by the time they were discharged from the hospital. And the PFTs showed significant improvement at the 6-month follow-up after surgery.

Seboldt et $\mathrm{al}^{15}$ and Singh et $\mathrm{al}{ }^{16}$ in their study documented that changes in pulmonary functions were irreversible, but in contrast Rhodes et al showed that the PFTs were reversible. ${ }^{5}$ Thus it is evident that in the course of the disease, a point is reached where valve replacement will not improve the lung functions, although it may improve the class of dyspnea. Hence it is important to intervene early to prevent irreversible changes in the lungs. ${ }^{11}$

Study limitations: A small number of patients was enrolled in this study. This is an observational study conducted in a single center. All patients underwent mitral valve replacements with mechanical prosthetic bileaflet valves by single surgical team, which may not be applicable to all. NYHA class IV patients were not included in this study, so the irreversibility of lung functions could not be assessed.

\section{Conclusion}

This study demonstrated that most patients with isolated severe MS present with restrictive pattern of lung function derangements. These patients had significant reduction in $\mathrm{FEV}_{1}, \mathrm{FVC}, \mathrm{FEV}_{1} / \mathrm{FVC}$ ratio, FEF 25-75\%, MVV, and PEFR preoperatively. Except for PEFR, all other values of PFTs improved significantly after mitral valve replacement surgery. There was also statistically significant improvement in NYHA class after mitral valve replacement in patients with MS. However, the clinical improvement does not correlate well with improvements in many spirometric tests, except PEFR. It needs longer-term follow-up to assess the complete changes in PFTs after mitral valve replacement. 


\section{Conflict of Interest}

All authors declare that they have no conflict of interest.

\section{Funding}

All authors declare that they do not receive any research grants from any company, have not received a speaker honorarium from any company, do not own any stock in any company, and are not members of a committee.

\section{Statement of Human Rights/Ethical Approval}

All procedures performed in this study were in accordance with the ethical standards of the institutional and national research committee and with the 1964 Helsinki declaration and its later amendments or comparable ethical standards.

\section{Informed Consent}

Informed consent was obtained from all individual participants included in this study.

\section{References}

1 Otto CM, Bonow RO. Valvular heart disease: mitral stenosis. In: Braunwald Heart Disease. 8th ed. Philadelphia, PA: Saunders; 2008

2 Rahimtoola SH. Hurst's The Heart. 12th ed. New York, NY: McGraw-Hill Medical; 2008

3 Gómez-Hospital JA, Cequier A, Romero PV, et al. Partial improvement in pulmonary function after successful percutaneous balloon mitral valvotomy. Chest 2000;117(3):643-648

4 Garbagni R, Angelino PF, Brusca A, Minetto E. Residual lung muscle function in patients with mitral valve disease. Am J Med 1980;69:867-873

5 Rhodes KM, Evemy K, Nariman S, Gibson GJ. Relation between severity of mitral valve disease and results of routine lung function tests in non-smokers. Thorax 1982;37(10):751-755
6 Palmer WH, Gee JBL, Bates DV. Disturbances of pulmonary function in mitral valve disease. Can Med Assoc J 1963;89(15):744-750

7 Kadam PP, Pantvaidya SH, Jagtap SR, Rajgor KD. Effect of closed mitral valvotomy on spirometric pulmonary function tests in mitral stenosis. J Postgrad Med 1997;43(2):38-40

8 Chatterji RS, Panda BN, Tewari SC, Rao KS. Lung function in mitral stenosis. J Assoc Physicians India 2000;48(10):976-980

9 Saxena P, Luthra S, Dhaliwal RS, Rana SS, Behera D. Early changes in pulmonary functions after mitral valve replacement. Ann Thorac Med 2007;2(3):111-117

10 Mundhra SH, Mundhara KS, Thakkar RM, Ninama K, Parmar $\mathrm{H}$. Pulmonary function test in mitral valve disease. IAIM 2015;2(8):24-29

11 Yoshioka T, Nakanishi N, Okubo S, Kunieda T, Ishikura F, Nagata $\mathrm{S}$. Improvement in pulmonary function in mitral stenosis after percutaneous transvenous mitral commissurotomy. Chest 1990;98(2):290-294

12 Dogliotti GC, Angelino PF, Brusca A, et al. Pulmonary function in mitral valve disease; hemodynamic and ventilatory studies. Am J Cardiol 1959;3(1):28-39

13 Wellnhofer E, Cramer C, Dreysse S, Fleck E. Lung water, hemodynamics and dyspnea before and after valvuloplasty in mitral stenosis. Int J Cardiol 2000;75(2-3):217-225

14 Chandra A, Srivastava S, Dilip D. Spirometric changes following open heart surgery on rheumatic mitral valves. Asian Cardiovasc Thorac Ann 1998;6:28-33

15 Seboldt H, Stunkat R, Keppeler F, Hoffmeister HE, Hilpert T. [Reversibility or irreversibility of pulmonary function changes after cardiac surgery on insufficient or stenotic cardiac valves (author's transl)]. Thoraxchir Vask Chir 1975;23(4):431-436

16 Singh T, Dinda P, Chatterjee SS, Riding WD, Patel TK. Pulmonary function studies before and after closed mitral valvotomy. Am Rev Respir Dis 1970;101(1):62-66 